\title{
Dynamic water gravity rotation for endoscopic submucosal dissection: changing the location of the lesion
}

A 57-year-old man was admitted to our hospital for endoscopic submucosal dissection (ESD) for early gastric cancer. The lesion was located at the anterior wall of the proximal antrum to the lower body. After incision [1,2], about $350 \mathrm{cc}$ of distilled water was infused into the stomach ( Fig. 1). The weight of the water changed the shape of the stomach, so that the anterior wall rotated from the 9 o'clock direction to the 6 o'clock direction ( Fig.2). Repositioning the lesion made it easier to perform dissection using an insulation-tipped diathermic knife-2 (IT-2) ( Fig.3). As the final step, we aspirated water to reposition the lesion back to 9 o'clock, so that we were able to cut the edge of the lesion more efficiently ( $\bullet$ Fig.4).

It is technically difficult to dissect a lesion at the anterior wall of the proximal antrum to the lower body, because of partially obstructed access for knives and a smothered operation field. The IT- 2 has advantages, including a low risk of perforation and shorter operation times, but blind operation increases the risk of accidental perforation and bleeding [3]. We used dynamic water gravity rotation (DWGR) to obtain clearly visualized dissecting points and a precise approach by the IT-2. Filling the fundus with water results in counterclockwise rotation of the stomach and enables the IT-2 to approach the inflated submucosa in a precise parallel manner. The efficacy of dissection by the IT- 2 is maximized when the blade is parallel to the inflated submu- cosa. By the removal of water, the lesion can be relocated back to 9 o'clock, therefore making it easier to cut the edge of the lesion.

We conclude that DWGR is useful for relocating gastric lesions to facilitate ESD, especially for lesions at the anterior wall of the proximal antrum to the lower body.

Endoscopy_UCTN_Code_TTT_1AO_2AC

Competing interests: None

\section{H. H. Kim ${ }^{1}$, S. R. Choi ${ }^{2}$, H. W. Lee ${ }^{1}$, D. H. Ahn' , E. K. Kang ${ }^{3}$, M. H. Kwak ${ }^{3}$}

${ }^{1}$ Department of Internal Medicine, Kosin University College of Medicine, Busan, Korea

2 Department of Internal Medicine, Dong-A University College of Medicine, Busan, Korea

${ }^{3}$ Department of Diagnosis, Gospel Hospital, Busan, Korea

\section{References}

1 Ono H, Kondo H, Gotoda T et al. Endoscopic mucosal resection for treatment of early gastric cancer. Gut 2001; 48: 225-229

2 Fujishiro M, Kodashima S, Goto $O$ et al. Technical feasibility of endoscopic submucosal dissection of gastrointestinal epithelial neoplasms with a splash-needle. Surg Laparosc Endosc Percutan Tech 2008; 18: $592-597$

3 Ono H, Hasuike N, Inui T et al. Usefulness of a novel electrosurgical knife, the insulationtipped diathermic knife-2, for endoscopic submucosal dissection of early gastric cancer. Gastric Cancer 2008; 11: 47-52

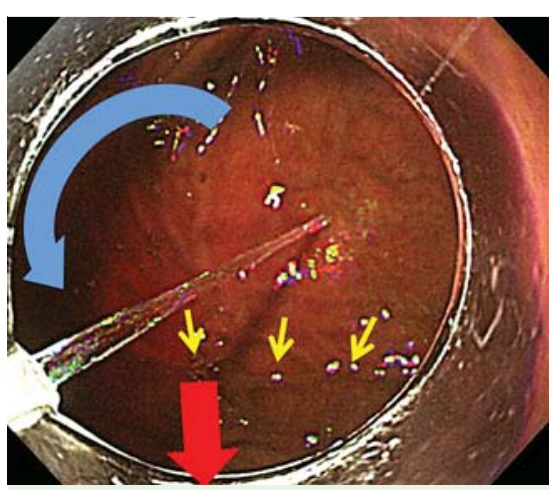

Fig. 1 Distilled water is infused into the fundus of the stomach (yellow arrows). The direction of gravity (and water movement) is indicated by the red arrow, and the direction of the rotation of the stomach is marked by the blue arrow.

\section{Bibliography}

DoI http://dx.doi.org/

10.1055/s-0032-1310020

Endoscopy 2012; 44: E283-E284

(c) Georg Thieme Verlag KG

Stuttgart · New York

ISSN 0013-726X

\section{Corresponding author}

\section{S. R. Choi, MD}

Department of Internal Medicine

Dong-A University College of Medicine

Dongdaesin-dong 3-ga 1

Seo-gu

Busan 602-715

Korea

Fax: +82-51-2402087

sychoi@dau.ac.kr

- Fig. 2 a, b, 3 and 4a, b see following page. 

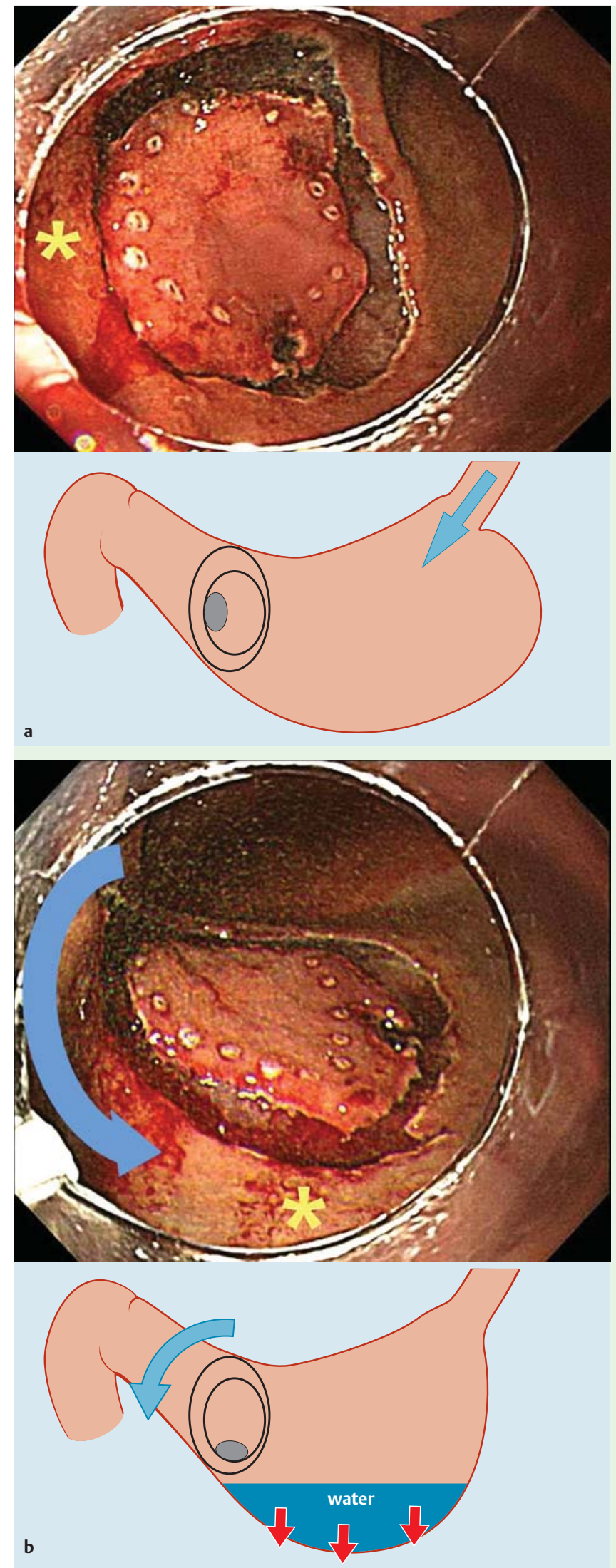

Fig. 2 a The lesion (asterisk) is observed at 9 o'clock before performing the dynamic water gravity rotation (DWGR). b After filling the fundus of the stomach with water, the shape of the stomach is changed by the effect of gravity on the water, and the lesion (asterisk) is rotated to $6 o^{\prime}$ clock; the blue arrow indicates the counterclockwise rotation, and the red arrows mark the direction of the effect of gravity, caused by the added water.

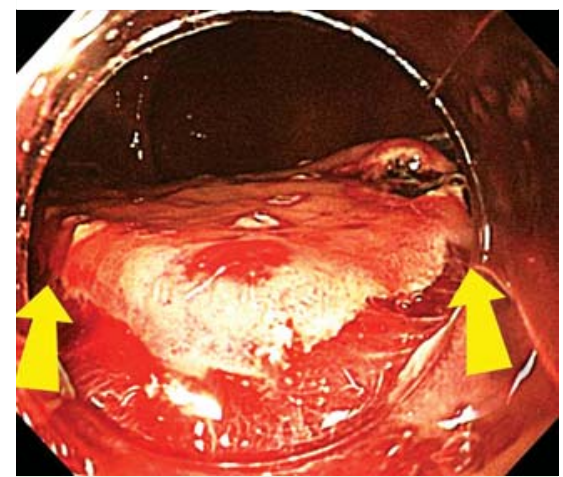

Fig. 3 The surgeon obtains a clear front view of the dissection point. The dissection point is parallel with the axis of the endoscope, and therefore also parallel to the insulation tipped diathermic knife-2 (IT-2) (yellow arrows).
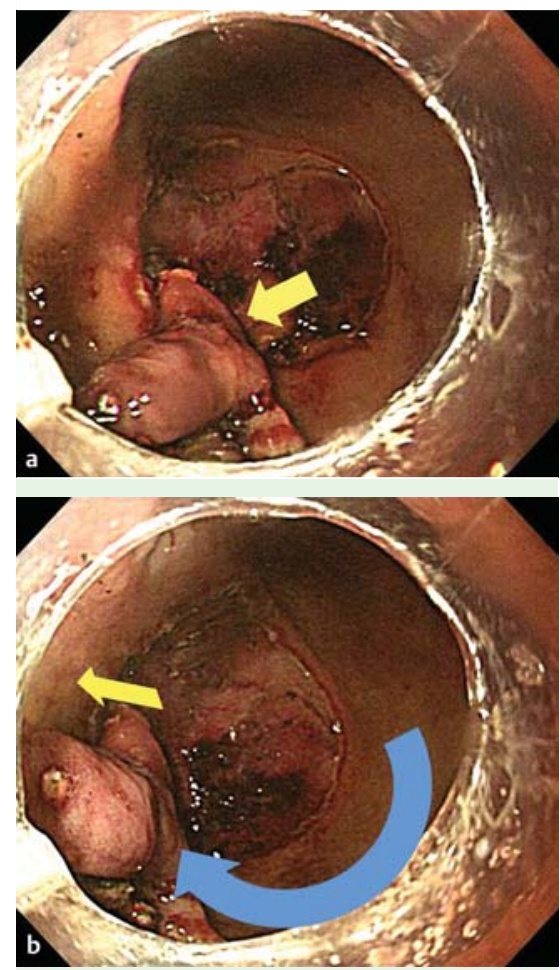

Fig. 4 a In the final step, with water in the stomach, the lesion is observed at the 6 o'clock position and obscures the final cutting point (arrow). b After aspirating water from the stomach, the lesion rotates to the 9 o'clock position (blue arrow), and the smothering flap also migrates to the point where the surgeon can handle it more easily (yellow arrow). 